\title{
Tianguis. Emergencia de ciudades temporales dentro de la ciudad. Ocupación espontánea del espacio público: el caso de Tlacolula
}

\author{
Bruno Seve. Universidad Politécnica de Cataluña, Barcelona, España. \\ Fabricio Lázaro-Villaverde. Universidad Autónoma Benito Juárez de Oaxaca, \\ Oaxaca, México. \\ Juan-Manuel Gastéllum-Alvarado. Universidad Autónoma Benito Juárez de \\ Oaxaca, Oaxaca, México. \\ Ernest Redondo. Universidad Politécnica de Cataluña, Barcelona, España.
}

RESUMEN | Son cada vez más los proyectos urbanos que evolucionan hacia un modelo más inclusivo y participativo, sinónimo de planificación urbana democrática. No obstante, la participación real de la población, en su esencia, es una práctica milenaria en algunas comunidades. Existen de hecho, todavía, en el mundo, arquetipos de participación urbana, como en México los mercados ambulantes o "tianguis". Este artículo analiza varias facetas (geográfica, histórica, social, espacial y arquitectónica) del tianguis de Tlacolula de Matamoros, invitando a estudiantes y profesores a explorar e interactuar con la comunidad, utilizando varios medios para la recolección de datos, como el dibujo urbano, apuntes, fotografías y las entrevistas. Los resultados muestran una organización minuciosa y colectiva del espacio con una larga tradición, a pesar de una precarización creciente, con usuarios y usuarias que acuden desde hace años al lugar, con puestos autoconstruidos en los que destaca una variedad de microarquitectura.

PALABRAS CLAVE | espacio público, participación ciudadana, sustentabilidad urbana.

ABSTRACT $\mid$ An increasing number of urban projects are evolving towards a more inclusive, participatory model that is synonymous with democratic urban planning. However, in some communities, real participation in its essence is an ancient practice in some communities. In fact, archetypes of urban participation still exist in the world, as in Mexico, in the form of street markets or "tianguis". This paper analyses various facets (geographical, historical, social, spatial, and architectural) of the Tianguis of Tlacolula de Matamoros. Students and professors were invited to explore and interact with the community using various means for data collection, such as urban sketching, notes, photographs, and interviews. The results show a thorough, collective organization of the space with a long tradition, despite growing precariousness. Some users have been going there for years, and there are self-built stalls in which a wide variety of microarchitecture stands out.

KEYwORDs | public space, citizen participation, urban sustainability.

Recibido el 31 de enero de 2020, aprobado el 15 de agosto de 2020.

E-mails: B. Seve, bruno.seve@upc.edu | F. Lázaro-Villaverde, fabriciouabjomx@gmail.com | J. Gastéllum-Alvarado, gastel_@hotmail.com

E. Redondo, ernesto.redondo@upc.edu 


\section{Introducción: De tianguis y de sistemas emergentes}

"Fui de mercado en mercado por años enteros, porque México está en sus mercados".

(Neruda, 1974)

A partir de los ańos setenta, y en numerosas ciudades del mundo, el reclamo por la ciudad impulsó demandas de participación que ahora resurgen en los procesos urbanos y arquitectónicos. La regeneración urbana sostenible supone trabajar junto a la población para transformar las ciudades, haciéndole colaborar en la creación. Esto significa también un cambio en el papel del arquitecto y urbanista, que debería tener a su alcance una metodología de participación, trabajando transversalmente con otros especialistas. Existen múltiples facetas de la arquitectura participativa, pero también malentendidos y ejemplos de falsa participación, descritos también en textos teóricos como A ladder of citizen participation (Arnstein, 1969). No obstante, puede también abordarse la participación desde su significado esencial. De hecho, la palabra 'participación' está compuesta del verbo intransitivo "participar" y del sufijo "ción", que indica efecto, hecho o acción. Etimológicamente, el verbo 'participar' viene del latín participare (tomar parte de algo), compuesto de pars, partis (parte) y el verbo capere (tomar, agarrar). La participación es, entonces, el hecho de tomar parte. En algunas ocasiones, la participación "real" de la población, en su esencia, es una práctica milenaria. Existen de hecho, todavía, en algunas partes del mundo, arquetipos de participación urbana, como en México. El tequio, por ejemplo, es un trabajo colectivo que cada vecino de una ciudad o de un pueblo está obligado a ofrecer a su comunidad, para poder beneficiarse de los derechos comunitarios, como la vivienda. ${ }^{1}$ Pero también lo son los mercados ambulantes, llamados en México "tianguis", donde los usuarios se autoorganizan, ocupan el espacio urbano (o rural) para intercambiar bienes, servicios, información de todo tipo y establecen una serie de lazos personales inherentes a la creación de comunidad. El estudio de estas dos prácticas participativas es extremadamente interesante, ya que representan ejemplos vivos de un tipo de organización espacial, social y comunitaria. Entendemos aquí la autoorganización como aquel proceso en el cual alguna forma global de orden surge de las interacciones de la comunidad local, que forman un sistema inicialmente desordenado.

En el municipio de Tlacolula de Matamoros, a unos 30 km de Oaxaca de Juárez, capital del estado de Oaxaca en México, el mercado histórico dominical forma parte de un sistema de mercado de los valles centrales de Oaxaca. Representa una acción semanal, en la cual los usuarios participan y autoconstruyen de manera efímera, sin planificación aparente, una ciudad dentro de la ciudad.

Los mercados efímeros en los espacios públicos, o las plazas de mercados, son una muestra clara de involucración de los habitantes y de la vida de barrio en las ciudades del mundo. Desde un punto de vista antropológico, son lugares donde

1 La palabra tequitl como tributo y tequitiliztli, como trabajo, consiste en una contribución no remunerada para la comunidad (De Molina, 1555; Hernández, 1996). Sigue en vigor, por ejemplo, en el estado de Oaxaca, en el cual se autoconstruyen, se arreglan y se limpian espacios públicos, se plantan árboles, etcétera. 
se intercambian no solo productos, sino también información de todo tipo, lo cual permite el establecimiento de lazos personales y grupales de comunidad. Sin embargo, y pese a tales ventajas, el tema de los mercados informales que ocupan el espacio público plantea preguntas difíciles de responder; por ejemplo: ¿está el derecho al trabajo por encima del derecho al espacio público? ¿Deberíamos regular el uso del espacio, como hacen -a veces de manera excesivamente autoritaria- algunas ciudades de Europa, o dejarlo estar así, como en las impresionantes agrupaciones de tianguis en México?

En el caso de Ciudad de México, se puede considerar que los mercados de rueda (o tianguis) son apropiaciones del espacio público que articulan una forma colectiva de ciudad más compleja que las normas de planeación y regulación de uso de suelos impuestas por las autoridades. "Un efecto de entropía del dominio público y de la ciudad misma: un espacio no tanto como producto concreto sino como ensamblaje social colectivo" (Lazo, 2006, p. 85). Es un reto que hoy afrontan numerosas urbes, tanto en América Latina como en Asia, lo que podemos observar en el estudio ejemplar de Kim (2015), que explica cómo se organiza el espacio público de la ciudad de Ho Chi Minh, en Vietnam, a través del uso informal de sus aceras con todo tipo de actividades, y que cuestiona tanto la informalidad como la idea de la ciudad homogénea, reluciente, con regulaciones autoritarias del espacio público, como en el caso del modelo Barcelona. Este último, descrito por el famoso antropólogo Delgado (2007) como un supermodelo, convierte la ciudad en víctima de una atracción turística excesiva. Diseñada por y para el turismo con visión internacional, la capital catalana ha conocido los efectos inmobiliarios de tal tendencia en estas últimas décadas, lo que nos recuerda y plantea una vez más: ¿para quién hacemos la ciudad?

Según relata Bravo (2016), el urbanista y pensador David Harvey, en un encuentro en un mercado popular en Quito, Ecuador, dice que no se puede hacer ciudad sin replantearse el funcionamiento de nuestras economías: "Imaginemos Quito sin mercados como éste. Imaginemos el centro histórico de Quito sin población indígena. Imaginemos un Quito donde un turista pueda ir de iglesia maravillosa a iglesia maravillosa sin ver en ningún momento a nadie diferente. Puede parecer descabellado, pero es lo que los urbanizadores están proponiendo ahora mismo. Eso es lo que llaman modernizar la ciudad, eso es matar la ciudad...". "Cada vez vemos más ciudades construidas por principios comerciales. Es lo que el capitalismo hace, de lo que va. Si queremos cambiarlo, tenemos que cambiar el capital”.

Por otra parte, podemos ver los mercados como espacios que se ordenan desde un caos y crecimiento orgánico, donde se regeneran redes y sistemas emergentes. La emergencia, como lo describe el informático Johnson (2001) en su libro Sistemas emergentes: o qué tienen en común hormigas, neuronas, ciudades y software, ocurre cuando un sistema de elementos relativamente simples se organiza espontáneamente y sin leyes explícitas, hasta dar lugar a un comportamiento inteligente (inteligencia "de abajo hacia arriba"). Estos sistemas pueden ser las colonias de hormigas, estudiadas por la profesora Gordon (2010); cerebros humanos, pero también los famosos tianguis de México. A primera vista, en los tianguis, aparentemente caóticos, cada elemento es distribuido libremente, sin obedecer a ninguna regulación o leyes de geometría. No obstante, al cambiar el punto de vista a un nivel aéreo, 
se puede reconocer en este "caos" un sistema emergente autoorganizado, al menos de manera plástica, como ilustran las magníficas fotografías aéreas del gran artista Yann Arthus-Bertrand (Figura 1). Los tianguis en la Ciudad de México, cubiertos con lonas diversas, aparecen desde el cielo como obras abstractas y homogéneas. Debajo de las lonas se encuentra un mercado ruidoso, autoorganizado con estantes de frutas, vegetales, plantas medicinales, especias, artesanías, ropas y todo tipo de accesorios para la vida cotidiana y recreativa. Actualmente los tianguis han evolucionado socialmente y se localizan en la mayor parte de poblaciones de la nación mexicana y algunos países de Centroamérica, como entes autosuficientes generalmente no oficiales. Representan también un rompecabezas para los gobiernos, tanto por los riesgos para la salud que representan, inseguridad y oferta de productos robados, como por los problemas que pueden causar a la movilidad urbana. En la Ciudad de México, los tianguis ${ }^{2}$ están muy aceptados popularmente y son apreciados por visitantes de todas las clases y culturas, sobre todo por su atmósfera social, el contacto con los vendedores y por las especialidades tradicionales que ofertan. Según los datos de la Secretaría de Desarrollo Económico, existen en la capital mexicana 1.420 tianguis, con 46.273 ofertantes que distribuyen un $20 \%$ de los productos básicos, y representan el sustento económico de 800.000 personas. ${ }^{3}$

A continuación, el análisis se centra sobre un tianguis tradicional de Tlacolula de Matamoros, donde perduran todavía sistemas de trueque y que ofrece un panorama muy diferente de los "mercados de rueda" de la Ciudad de México. Nuestro interés por estudiar un tianguis tradicional parte de la intuición de que representa un sistema emergente autoorganizado por excelencia, que depende de diversos factores humanos, históricos, geográficos, etcétera, pero también arquitectónicos. Esta investigación se ha conducido desde distintas perspectivas disciplinarias para entender esta forma peculiar de transformar (aunque sea un día a la semana) el espacio urbano desde la población. Esta visión transdisciplinar concuerda también con la idea de que la planeación urbana debe, sin lugar a dudas, hacerse desde múltiples facetas y perspectivas, con la intervención de actores con lógicas diferentes (Ascher, 2010). Muxí y Gutiérrez (2011) explican de hecho cómo "la construcción de la ciudad futura se ha de nutrir de diversidad y complejidad, de una práctica inclusiva que incorpore las múltiples variables de la realidad, basándose en un urbanismo de abajo a arriba" (p. 13). En este contexto, no se puede hablar de participación o de urbanismo de abajo a arriba sin entender ejemplos vivos de sistemas autoorganizados desde la misma población.

Para Turner (2018), experto en autoconstrucción, el asentamiento urbano incontrolado es una manifestación de procesos de crecimiento urbano normales (la autoconstrucción), bajo condiciones históricas anormales (fuera de control por la atracción nunca vista de las grandes metrópolis). Y, entonces, los tianguis también son manifestaciones de ocupación normal del espacio público, pero que,

2 También reconocidos a partir de la década de 1970 como mercados sobre ruedas.

3 Este dato varía seguramente hoy en día, tratándose de un dato del 2010. En las noticias de la página internet de la Asamblea Legislativa del Distrito Federal 2016 para explicar la regulación de tianguis en Ciudad de México, citan a la secretaria de Desarrollo Económico, Laura Velázquez. Consultado el 24/08/2018. 
dependiendo de sus contextos, pueden llegar a ser incontrolables e inseguros; o, en otros contextos, diversos, seguros y viables. Esto es lo que pretende demostrar este artículo, partiendo del tianguis como fenómeno tradicional construido por la sabiduría de su población. Lo que este artículo quiere aportar a la bibliografía actual es una metodología multidisciplinar de análisis urbano, con un enfoque final sobre la organización espacial y arquitectónica del tianguis tradicional de Tlacolula de Matamoros, para entender el funcionamiento, la viabilidad y las características de este sistema complejo.

\section{FIGURA I | Vistas aéreas de tianguis}

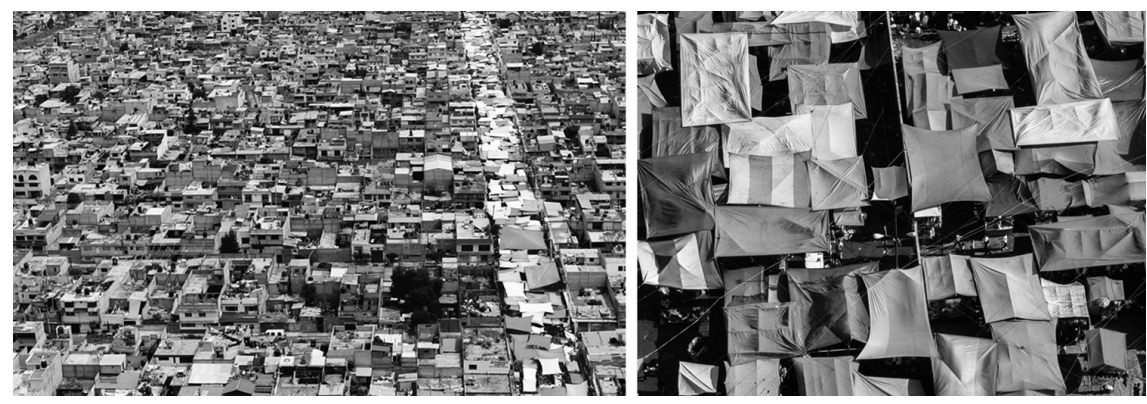

FUENTE: FOTOGRAFÍAS DE YANN ARTHUS-BERTRAND

\section{Tianguis de Tlacolula de Matamoro}

El tianguis indígena de Tlacolula de Matamoros (22.545 habitantes), a unos 30 $\mathrm{km}$ de la ciudad de Oaxaca de Juárez (300.000 habitantes), es un caso de estudio ideal porque, aunque haya evolucionado, sigue siendo un ejemplo tradicional de mercado al aire libre, con productos locales de la región, colores y fragancias difíciles de describir en este artículo. El hecho es que el visitante, al recorrer el mercado, sabe que está experimentando un lugar temporal único y raro (Figura 2). Para el presente artículo, la recopilación de datos ha sido mixta, realizada a partir de diversas fuentes: documentos teóricos (históricos, sociológicos y geográficos); fotografías aéreas con un dron, para entender la ocupación espacial en las calles de la ciudad; talleres de experimentación a pie de calle, con y sin el mercado dominical, con el uso de fotografías, dibujo y entrevistas a la población local. El objetivo ha sido entender la estrecha relación que existe entre la arquitectura efímera del sistema mercantil, el lugar y la geografía, y sus usuarios y usuarias, principalmente las y los marchantes.

A continuación se describen los resultados de nuestra investigación, que involucró tanto a profesorado y alumnado de la Escuela Técnica Superior de Arquitectura de Barcelona (ETSAB) de la Universidad Politécnica de Catalunya (UPC) como de la Facultad de Arquitectura de la Universidad Autónoma Benito Juárez de Oaxaca (UABJO), partiendo de la relación y el origen de aquel tianguis, y después enseñando la organización territorial y urbana a través de la recopilación de datos con las personas comerciantes. 
FIgura 2 | Tianguis de Tlacolula de Matamoros. Atmósferas y actividades dominicales
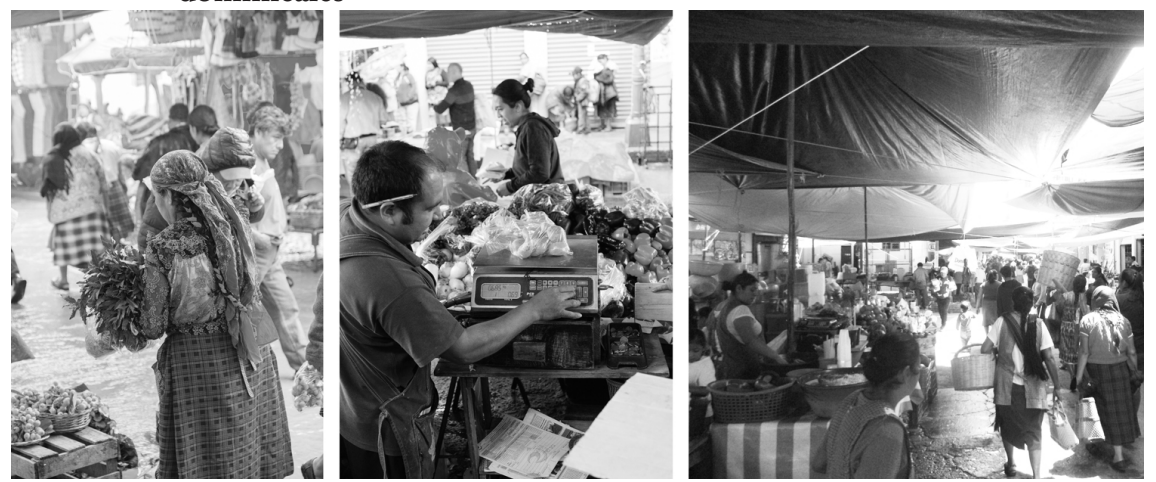

FUENTE: FOTOGRAFÍAS DE BERNARDO DE ANDA Y BRUNO SEVE

Relación con la capital oaxaqueña y origen histórico:

el sistema de mercados tradicionales

Durante la época prehispánica, en distintos lugares de Mesoamérica se hacía referencia a la palabra náhuatl "tianquiztli", cuyo significado es "intercambio" o "mercadeo" de productos, posteriormente conocida como tianguis, actividad que constituyó una de las partes fundamentales de cada cultura que la practicaba en esa época en la región. De acuerdo con Álvarez (2008), es probable que algunas plazas abiertas de la ciudadela de Monte Albán ${ }^{4}$ hayan sido utilizadas o creadas para actividades de trueque o intercambio, lo que preconfiguraría el origen de los tianguis oaxaqueńos. Tal posibilidad guarda relación con el hecho referido por Chance (1993) en torno a que, a la llegada de los españoles a los valles centrales de Oaxaca, encontraron un desarrollado sistema de mercadeo regional que tenía lugar cada cinco días en determinados poblados, con posibilidad de un amplio intercambio comercial. ${ }^{5}$ Durante la época II de Monte Albán (del año 100 a.C. al 200 d.C.), la sociedad zapoteca dominaba todos los pueblos de la región. Se establecía un estado expansionista a partir de una ciudad con distritos organizados jerárquicamente por pueblos grandes, bajo los cuales se ubicaban aldeas y, en la parte inferior, otras pequeñas aldeas que producían cultivos y artesanías (Marcus, 2008). Tal vez esta condición se replicaba con el establecimiento del sistema de mercadeo que encontraron los españoles a su llegada al gran valle de Oaxaca. Al respecto, Chance (1993) ubica documentos que prueban la existencia durante el periodo virreinal de otros cuatro sitios de mercadeo, que posiblemente funcionaban desde el periodo prehispánico; uno de ellos se encontraba en Tlacolula, fechado en $1579,{ }^{6}$ el cual perdura hasta nuestros días.

El sitio arqueológico de Monte Albán se localiza a unos 8 a $10 \mathrm{~km}$ de la ciudad de Oaxaca de Juárez. Fue una de las ciudades más importantes de Mesoamérica, fundada alrededor de 500 a.C.

5 El mismo autor identifica estos lugares en la actualidad con Etla, Santa Elena (probablemente Tlapacoya), Chichicapam y la Huaxyacac Azteca.

6 Los otros sitios de mercado son: San Andrés Huayapam (fechado en 1653); San Juan Chilateca (1743); Ocotlán (1764). 
La ubicación que mantuvo Antequera ${ }^{7}$ (luego Oaxaca de Juárez) como sitio de paso hacia Guatemala o Perú con fines de conquista y comercio, permitió a las autoridades españolas insertar en ella funciones administrativas de fiscalización, control de tráfico de personas y mercancías, permisos para el uso de mulas de carga, así como la organización y conservación de caminos que pasaban por este territorio. Ello permitió que la localidad encontrase disposición para la venta e intercambio de productos (como trigo, maíz, árboles de castilla, factoría de tabaco, grana cochinilla, algodón, frutos nativos y moreras, entre muchos otros), que se promovían para su siembra en los campos del valle y los que se empezaban a producir en la ciudad, ${ }^{8}$ lo que explica que, en décadas posteriores, los españoles enfatizaran el control indígena con base en su sistema de mercadeo (Nolasco, 1981).

Los primeros cuarenta años posteriores a la llegada de los peninsulares al valle de Oaxaca se caracterizaron por la dependencia casi exclusiva de los indígenas como fuente principal para su alimentación, práctica de la agricultura y ganadería a pequeña escala. Sin embargo, los indígenas solo se conformaban con sembrar lo necesario para su consumo. Así lo corroboran documentos con diversas peticiones presentadas al rey por el cabildo de Antequera en 1532, para que ordenara a los indios del distrito que vendieran alimentos a los españoles de la ciudad (Taylor, s/f). De acuerdo con el mismo autor, en 1551, el cabildo de Antequera promulgó una orden para que se cultivaran más tierras indias, con el fin de cubrir las necesidades de demanda de granos que requería la ciudad. Para esos momentos, los espańoles ya practicaban la cría de ganado en predios indefinidos en todos los puntos alrededor de Antequera, con lo cual se promovió la construcción de inmuebles que denominaron "estancias ganaderas", las cuales evolucionaron con el tiempo. Para el siglo xvir ya contaban con límites territoriales bien definidos y se convertían en haciendas. Estas mismas se constituyeron en unidades económicas particulares dedicadas a abastecer mercados locales de granos y productos animales, lo que seguramente influyó en que se empezaran a establecer tianguis en el perímetro de algunas de ellas. Hacia el siglo XVIII, Antequera era sede de recaudación de tributo, control de mano de obra indígena y obtención de otros bienes a través del sistema de mercados. Sus edificios principales eran religiosos y administrativos, girando la ciudad alrededor de ellos y del espacio libre en que diariamente, por las tardes, se celebraba el mercado, mostrándose con mayor importancia el tianguis que se iniciaba el día viernes por la tarde, se mantenía durante todo el sábado y concluía la mańana del domingo. A tal acontecimiento concurrían habitantes de Antequera, avecindados de pueblos de la comarca, y pobladores de las sierras del norte y sur que bordeaban los valles centrales de Oaxaca. En esa época la ciudad se relacionaba y prosperaba en lo civil alrededor del comercio, desarrollaba la minería y consolidaba la propiedad privada de inmuebles convertidos en florecientes haciendas agrícola-ganaderas en manos de peninsulares (Nolasco, 1981). Aquello generaba una base económica propia, relativamente autónoma, y con condiciones básicas para convertir a la ciudad y

7 Denominación dada por los espańoles a Oaxaca de Juárez a partir de 1528 tras la llegada de Hernán Cortés como marqués del valle de Oaxaca.

8 En tenerías, molinos de trigo y cacao y manufacturas textiles, entre muchos otros. 
alrededores inmediatos en un núcleo urbano con sólida base comercial y productiva (Duhau, 1988).

Para los inicios del siglo xIx, el comercio experimentaba un nuevo repunte; la arriería se había convertido en una actividad próspera, y Oaxaca, en un centro indo-mestizo de distribución y concentración de productos. Con la independencia nacional, los indígenas dejaron de obedecer a los oficiales del rey, ya que sus nuevos explotadores serían los habitantes mexicanos de Oaxaca, pasando a convertirse el territorio citadino, de acuerdo con Nolasco (1981), de sede de dominación colonial española a ciudad-mercado para el control indígena. Evidencias documentales demuestran que durante el México dependiente, el gobierno oaxaqueño trataba de mantener un severo control de la legalidad y civilidad, tanto para otorgar permisos para el establecimiento de tianguis en algunas de las distintas plazas de poblaciones del estado (Archivo General del Estado de Oaxaca [AGEo], 1828) en torno a los inmuebles ocupados por haciendas particulares, ${ }^{9}$ así como para el día de la semana en que se efectuaban y la garantía de libertad o negativa para expender o transportar víveres y mercancías en ellos (AGEO, 1828). Otro documento ${ }^{10}$ hace referencia a la disposición del juez de Ixtlán para impedir que la "raya" o pago semanal a operarios de las minas ubicadas en pueblos cercanos se realizara los sábados por la noche, en el supuesto de que hacerlo los domingos por las mañanas prevenía los muchos desórdenes que sucedían pagando las noches de sábados. También se condicionaba la autorización de pago ligada a los días y horario de tianguis en plazas de mercado en Capulalpam los domingos, y en Ixtlán (poblaciones de la región Sierra Norte de Oaxaca), los lunes (AGEO, 1835).

Es notorio que, para esa época, las autoridades gubernamentales trataban de legalizar, normalizar y controlar todo lo que ocurría en los tianguis y mercados de los poblados del estado de Oaxaca, estableciendo, mediante documentos oficiales, las demarcaciones de los sitios de establecimientos comerciales, áreas libres para circulación, obligaciones, cuidados, aseo, mantenimiento o conservación, y condiciones en caso de arrendamiento de elementos o espacios sombreados, así como la actuación en casos de accidente o conflagración, entre otros aspectos (AGEO, 1858). Se enfatizaba de ese modo la mayor importancia de aplicación de cada aspecto mencionado en el cada vez más creciente tianguis de la ciudad de Oaxaca, pero sin descuidar el floreciente desarrollo del mercadeo que se popularizaba en poblados como Zaachila y Ocotlán (AGEO, 1875) y Tlacolula (AGEO, 1879). Para la última década del mismo siglo, ya se contaba con reglamentos para el funcionamiento de los mercados, así como registros detallados en cuadros sinópticos mensuales con la recaudación generada por cada producto, que tenían en cuenta sus características materiales y condiciones de calidad (AGEO, 1896).

Durante el siglo $\mathrm{xx}$, continúa la petición oficial para establecer tianguis y mercados en distintos puntos del centro físico de la ciudad de Oaxaca, pero concentrando la atención en torno a su mercado central principal, que incluía una red de tiendas de abarrotes y comercios de diversos giros donde los sábados se continuaba

9 Tal es el caso de la Hacienda del Socorro, en la Sierra Juárez.

10 Del mismo mes y año. 
practicando el tianguis semanal con la mayor concentración de "puestos" callejeros improvisados de todo el estado. Oaxaca cumplía así su función de central de abasto regional, pero subrayando su vocación comercial y consolidándose como ciudad mercado (AGEO, 1926). Nolasco (1981) expresa gráficamente, mediante un esquema, el importante lugar de la ciudad de Oaxaca como centro de un sistema mayor de mercados tipo solar, a partir de cuatro tipos de mercados: el principal, con sede en la misma localidad; Ocotlán y Tlacolula, los dos mercados secundarios; a otro gran número de ellos, pero más pequeńos en tamańo, los clasifica como mercados dependientes; y otra gran cantidad de estos, como mercados limitados, no existiendo relación entre sí de los mercados dependientes y los limitados, sino una conexión a través de los mercados secundarios y el principal (Figura 3). Este sistema se organiza a través de la recepción y envío de mercancías hacia mercados ubicados al este del estado de Guerrero y hasta el oeste de Guatemala.

Desde su aparición en la época prehispánica, el sistema de mercados ha continuado operando con algunas modificaciones; pero, en algunos sitios, de forma muy semejante hasta nuestros días. Según algunos investigadores, una de las características de estos mercados es que permanecen en los mismos lugares donde estaban establecidos los mercados prehispánicos del pasado (Diskin \& Cook, 1975; Warman, 1982). El tianguis dominical del municipio de Tlacolula de Matamoros ha mantenido un lugar importante dentro del citado esquema, ubicado en la actualidad en el lugar sobresaliente que durante cientos de años mantuvo el tianguis de la ciudad de Oaxaca. Con el paso de los años, los pobladores de la zona han cumplido el relevante papel de conservar el tianguis, elemento fundamental de la cultura zapoteca y derecho consuetudinario de sus antepasados (Cordero Avendaño de Durand, 1982), el mismo que aún guarda semejanzas con tianguis ancestrales a través de la práctica del trueque como forma de comercio. Tal práctica es un factor de conservación de las relaciones personales entre hablantes del idioma zapoteco y entre estos y los visitantes de diversas culturas, además de continuar contribuyendo con la mayor parte de intercambio económico entre los pueblos del valle de Tlacolula, y de estos con los del valle de Zimatlán y de Etla. Parecería ser que, si bien la llegada de los peninsulares con el desarrollo económico mencionado pudo canalizar (en algunas ocasiones limitarlo o, al contrario, catalizar) el sistema de mercado semanales, su organización en un día de la semana podría tener antecedentes en tiempo prehispánico (Cook \& Diskin, 1990; Grosso, 1989; Santos \& Mendoza, 2009). Hoy en día, cada región de los valles centrales cuenta con un día concreto de mercado (domingo, Tlacolula; martes, Centro, ciudad de Oaxaca; miércoles, Etla y Zimatlán; jueves, Zaachila y Ejutla; viernes, Ocotlán y Centro, ciudad de Oaxaca; y sábado, Centro, ciudad de Oaxaca). En todos los casos, parece claro que existe una real evidencia respecto de que el mercado de Tlacolula es parte de un sistema complejo que nació seguramente de los pueblos originarios de Oaxaca y fue evolucionando por las características geográficas e históricas del lugar. 
FIgURA 3 | Reinterpretación de la figura "Sistema de mercados de los valles centrales de Oaxaca”, idealizada por Nolasco (1981)
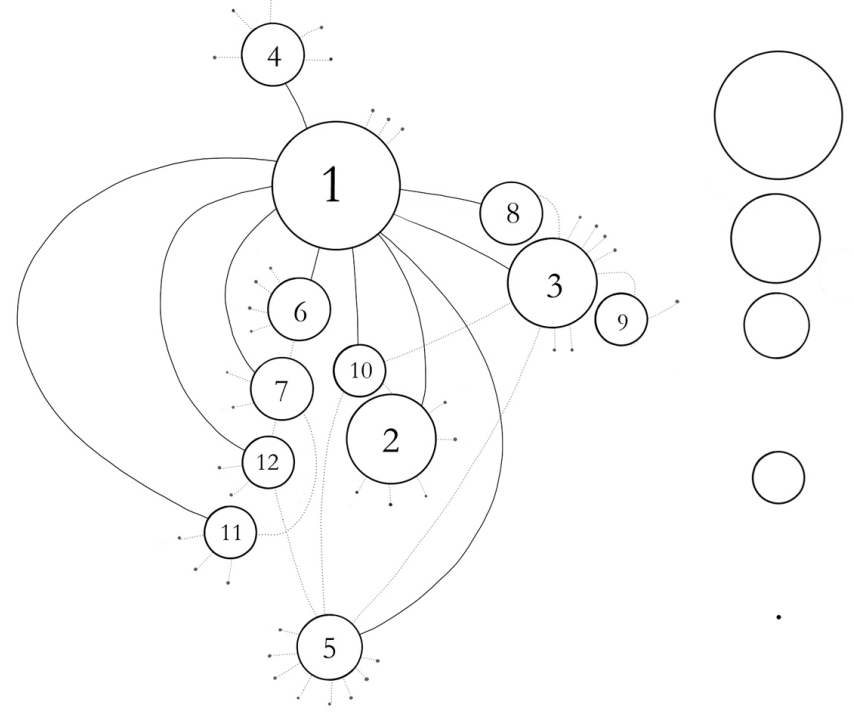

Mercado principal 1- Oaxaca de Juárez

Mercados secundarios 2- Ocotlán 3- Tlacolula

Mercados dependientes 4- Etla 5- Ejutla 6- Zaachila

7- Zimatlán

8- Teotitlán

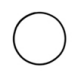

Mercados limitados

9- Mitla

10- San Antonino

11- Ayoquezco

12- Huixtepec

- Poblaciones participantes

FUENTE: ELABORADO POR BRUNO SEVE

\section{Análisis arquitectónico y sociológico del tianguis}

\section{Escala territorial}

Quienes acuden a vender, comprar o intercambiar sus productos, también vienen a socializar en el espacio público. Una de las características importantes de los tianguis de Ocotlán, Tlacolula, Etla, Zimatlán, Zaachila y Ejutla, es la existencia del trueque, todavía vigente en el mercado de Tlacolula (Malinowski \& De la Fuente, 1957). En el mercado dominical de Tlacolula, donde acuden aún mixes como zapotecas de la Sierra Juárez y del Istmo a vender sus productos, existe una real riqueza biocultural (Coronel, 2006; Malinowski \& De la Fuente, 1957). Otro estudio, más reciente, indica que la mayoría de comerciantes productores agrícolas tiene una edad media de 48 años, 90\% son mujeres, 78,95\% habla zapoteco además del español, y su procedencia es San Bartolomé Quialana (68,42\%), San Antonino (10,52\%); el resto (10,52\%), San Marcos Tlapazola, San Sebastián Abasolo, Cuajimoloyas y Sierra Juárez (Benítez Hernández \& Enríquez Valencia, 2018).

Nuestro estudio difiere significativamente de los estudios anteriores, pero los complementa, habiendo acompañado a más de 19 marchantes con entrevistas cualitativas y otras recopilaciones de datos. La masa comerciante representa una mayoría de mujeres (74\%), de una edad media similar a la registrada en los estudios anteriores (48 años), desde los 19 años hasta 67 años; de orígenes variados, que abarcan desde la ciudad de Oaxaca de Juárez (31\%), la región de Tlacolula cercana (42\%), a otras localidades situadas en el valle que siguen la misma lógica geográfica 
y topográfica. Los valles centrales, con altitud media de $1.500 \mathrm{~m}$, representan el gran corredor para llegar a Tlacolula de Matamoros, con la carretera internacional a la cual se unen ramificaciones perpendiculares (Figura 4) y rodeado por la Sierra del Norte y Sierra del Sur, con cerros de más de $3.000 \mathrm{~m}$. El tiempo medio de recorrido entre el lugar de origen y Tlacolula de Matamoros es de poco menos de una hora (55 min.), según nuestro estudio. El trayecto máximo recopilado es de unas dos horas, de Arrazola o Zaachila, mientras una parte goza de una proximidad que permite un recorrido de menos de 20 minutos (15\%). La mayoría se traslada en vehículo privado (camioneta) hasta Tlacolula de Matamoros, aunque algún comerciante se traslada en autobús desde la ciudad; por ejemplo Silvano, de 67 años, que tiene su mercancía y el armazón de puesto resguardado en casas-bodega in situ.

Los productos vendidos son diversos, pero suelen ser huaraches, ropa típica de la región, artesanías, cinturones, frutas (duraznos, manzanas, piñas provenientes de la sierra), verduras (nopales, calabazas, chayotes, chiles, cebollas), semillas, hortalizas (hierbas y flores del valle, maguey, orquídeas) y algunos granos y cereales como maíz, garbanzo, trigo y frijol. Hay incluso puestos de comida. Los productos vendidos suelen provenir directamente del medio en el que se originan, lo que puede verse como una práctica ecológica y local de gran interés. Cabe mencionar una vez más el reciente artículo de Benítez Hernández y Enríquez Valencia (2018) sobre la economía campesina local, en el cual se explica que el atractivo turístico ligado a este mercado histórico, junto con la neoliberalización que existe en los valles centrales de Oaxaca, han llevado a una situación cada vez más precaria del sistema y de sus actores: "Se pueden observar prácticas ancestrales debilitadas que luchan por subsistir en estos espacios que desde hace varios ańos forman parte del modelo neoliberal" (pp. 1091-1092). El estudio demuestra también que el sector primario representado en la región por la agricultura y ganadería se encuentra en una situación aún más precaria de explotación, puesto que su producción ha disminuido en 30 puntos porcentuales, al pasar de un $41 \%$ a un $11 \%$, y que una gran mayoría de los jóvenes busca trabajo en las ciudades.

No obstante, cabe mencionar que nuestro estudio revela que, de las 19 personas entrevistadas, solo dos comerciantes encuentran el trabajo difícil y desearían que sus descendientes se dedicaran a otro tipo de actividad. El resto considera el trabajo como noble, "bonito" y tranquilo, que se desarrolla en un ambiente amistoso y comunitario y que, si sus descendientes lo desean, podrían seguir con la tradición familiar. Destacan que, en algunos casos, se trata de maneras de vivir que perduran desde varias generaciones; como la seńora Valentina, de 45 años, que explica que su madre empezó con el puesto en 1935; o la señora Alicia, que lleva viniendo al tianguis desde hace más de 48 ańos. 
Figura 4 | Valles centrales de Oaxaca y Tlacolula de Matamoros. Origen y traslado de los participantes

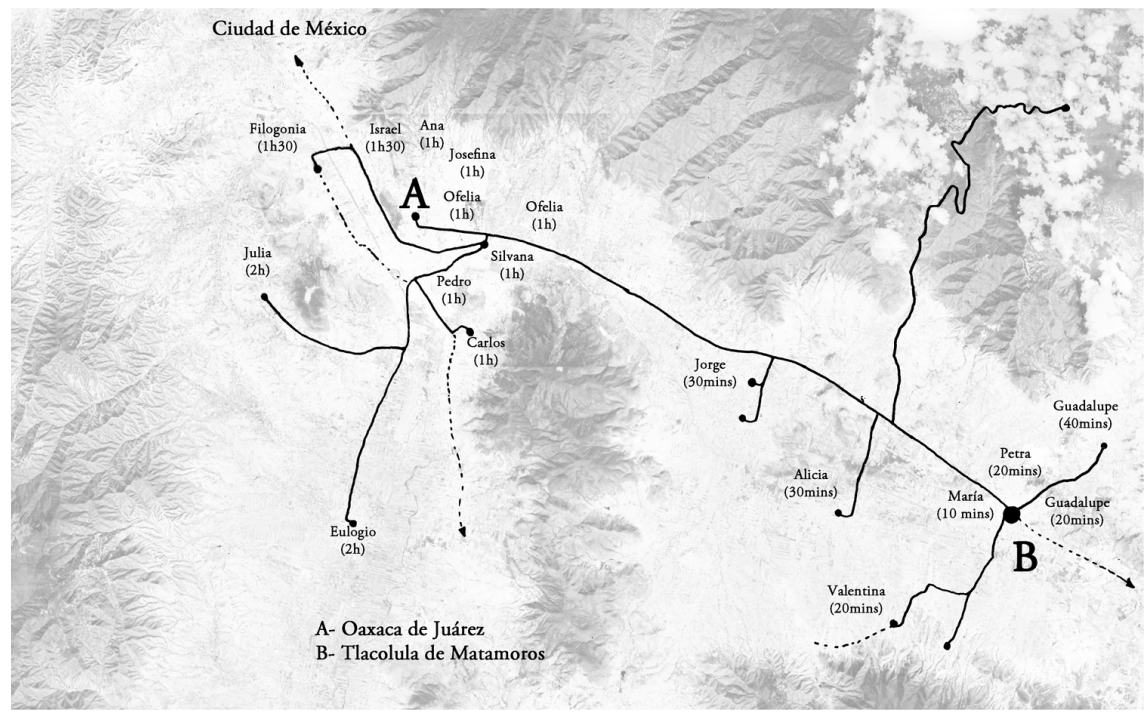

FUENTE: ELABORADO POR BRUNO SEVE

\section{Análisis espacial del tianguis: escala urbana}

El tianguis de Tlacolula de Matamoros se caracteriza por ubicarse de manera efímera, todos los días domingo de cada año desde la época prehispánica, hacia el lado sur de la actual carretera internacional Oaxaca-Tehuantepec, que conecta al noreste con Oaxaca en dirección de la Ciudad de México y hacia el suroeste, con Tehuantepec, hacia el océano Pacífico. Se circunscribe principalmente siguiendo el curso lineal de un eje norte-sur desde la parte media del templo Santa María de la Asunción, con su atrio, la plaza Central o Zócalo Municipal, hasta la carretera internacional. Con el transcurso de los ańos se han unido algunas calles, sobre todo en la porción central, con expendedores que ofertan sus productos y amplían la dimensión general del tianguis. En términos generales, alrededor de la iglesia Santa María de la Asunción el tianguis ocupa cuatro calles hacia el norte, tres calles hacia el sur, una calle hacia el oriente y una calle hacia el poniente. Este desarrollo transforma directamente las actividades urbanas cotidianas de los pobladores en más o menos 12 manzanas de la pequeña ciudad, e influye en el resto del distrito de Tlacolula, que se compone de 25 municipios en los cuales viven 117.032 personas (Centro de Información Estadística y Geográfica del estado de Oaxaca [CEIEG], 2010). El espacio público por excelencia del tianguis es la calle con aceras. La porción vial principal que ocupa el tianguis dominical son regularmente cuatro calles, con una longitud total de 860 metros, que se intercalan con la mayor cantidad de comercios fijos del casco urbano de Tlacolula. El tianguis constituye una porción importante del desarrollo de la avenida Benito Juárez, vialidad de acceso y distribución principal del área urbana central del municipio de Tlacolula (Figura 5 y Figura 6). 
FIgURA 5 | Localización del tianguis (en gris claro) en Tlacolula de Matamoros

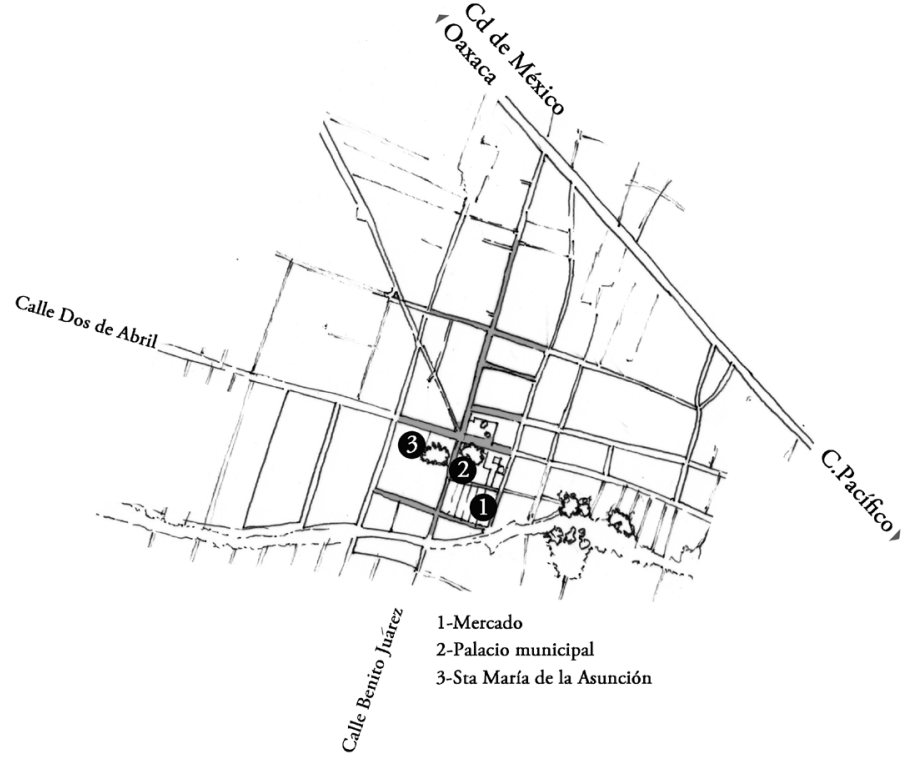

FUENTE: ELABORADO POR BRUNO SEVE

FIGURA 6 | La avenida Benito Juárez en un día ordinario y en un domingo

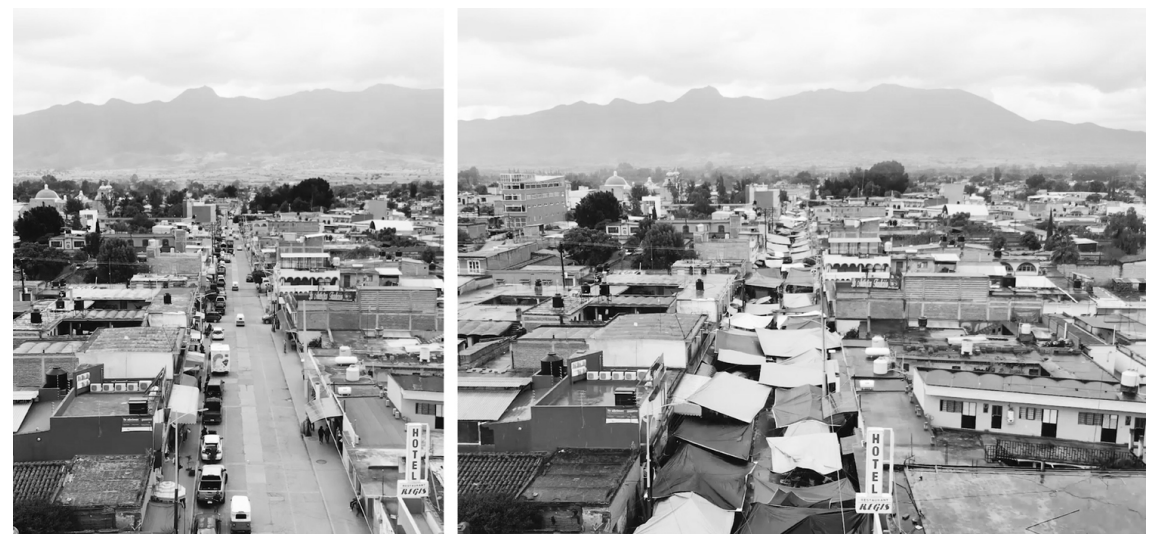

FUENTE: FOTOGRAFÍAS DE BERNARDO DE ANDA Y BRUNO SEVE

La avenida Juárez se compone de una calzada para los vehículos de 8,70 metros de ancho y aceras de 1,60 metros de ancho promedio (Figura 7 y Figura 8). En este tramo, los puestos del tianguis respetan sin distinción las aceras y los accesos del comercio establecido, aunque la distribución sigue su propia lógica. En la Figura 7 se aprecia cómo los puestos se configuran en franjas, con dos paseos laterales de 1,20 a 1,60 metros, y un paseo central de aproximadamente 3,9 metros, lo que deja 
a los puestos una anchura de 2,40 a 2,80 metros. Existen espacios de paso entre tianguis que permiten cruzar desde el paseo central a los laterales y, de esta manera al comercio establecido. Esta relación entre comerciantes establecidos y tianguistas se mantiene amistosa, hasta el punto de que los primeros llegan a reservar el espacio del tianguista habitual. Nuestra investigación muestra también que el $90 \%$ de los participantes considera que el ambiente es amistoso y comunitario.

\section{FIGURA 7 | Axonometría tipo de la avenida Benito Juárez}

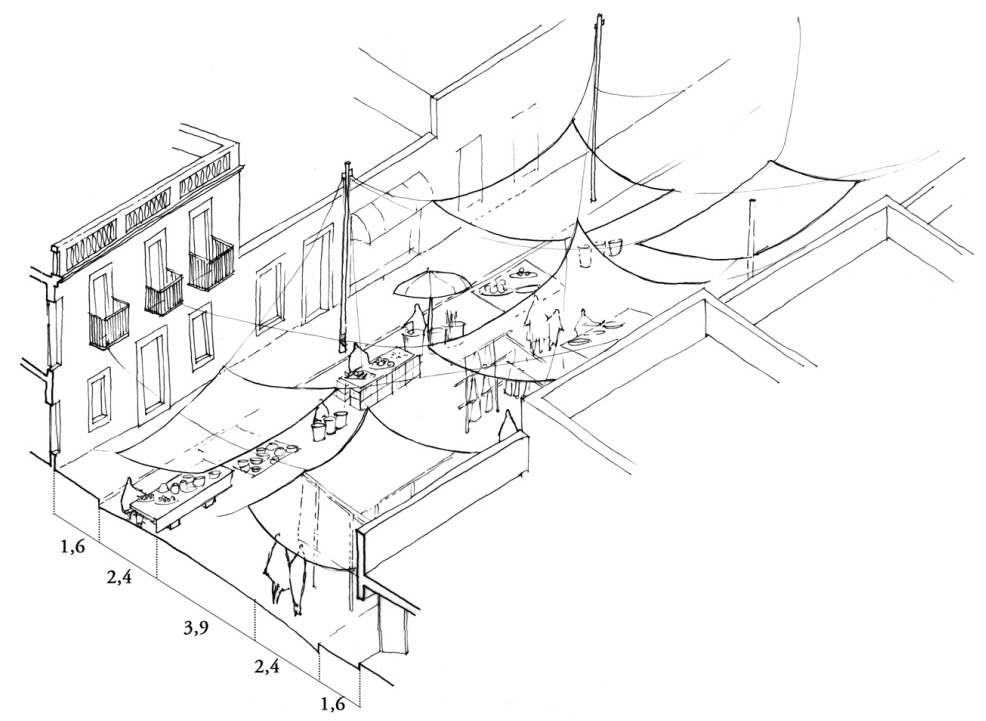

FUENTE: ELABORADO POR BRUNO SEVE

La colocación de los puestos es parecida en las calles transversales con desarrollo oriente-poniente, como el caso de la calle 2 de Abril. Esta zona se distingue de las demás por la venta de una incontable variedad de géneros comerciales, que van desde lo más natural o artesanal hasta productos industriales. La calle 2 de Abril, en su desarrollo hacia el oriente, evidencia mayoritariamente la venta de productos artesanales de carrizo, textiles, hilados y tejidos tradicionales, arcilla, y tallas de madera, entre otros; mientras que en su desarrollo hacia el poniente, el género de venta se diversifica al expender objetos y monedas antiguas, ropa usada, cosméticos y artefactos eléctricos, por citar algunos productos. A partir de la intersección con esta calle, el ancho de la avenida Juárez se reduce, con un espacio menor para los puestos de venta de tianguistas, y un ancho en la zona central de 5,10 metros y aceras laterales de 1,20 metros. En esta zona, la sección de la calle solo permite la colocación de los puestos colindantes hacia los límites del atrio, Palacio Municipal y plaza Central. Al interior de la plaza Central, las zonas libres, pasillos y jardines mantienen cotidianamente un uso de esparcimiento; los días de tianguis, una considerable porción del espacio es ocupada por artesanos alfareros, y otra menor admite 
la colocación de expendedoras de alimentos, como tortillas, elotes y tamales, así como la degustación informal de los mismos alimentos por distintos comensales. Esta zona se distingue de las demás por el predominio de venta de ropa de todo tipo.

En el entorno inmediato del Mercado Municipal, se conserva la misma configuración de los tianguistas por ocupar el espacio hasta el límite de las propiedades, siempre que no interrumpan la circulación y accesos hacia inmuebles particulares y comercios establecidos. En este sentido, la fachada del Mercado Principal, que dispone de pocas aperturas, permite la colocación de los tianguis directamente a ras del edificio. En esta área predomina la compraventa de objetos artesanales para el campo y la preparación de alimentos, especialmente los usados para la elaboración de comidas tradicionales de la región, así como aves de corral y ganado caprino vivo. Y, por extensión, es la zona donde aproximadamente antes de entrar la tarde, se visualizan distintos casos de activación del trueque mediante el ofrecimiento de esta modalidad hacia otros puestos de venta. Finalmente, cercano al mercado, se encuentra en la calle Manuel Doblado una cierta diferenciación en las características de los puestos, con divisiones realizadas mediante muebles de madera o pasillos delimitados por tejidos de carrizo, que guardan relación con el género comercial de muebles de madera y productos para el hogar que ahí se expenden.

\section{FIgURA 8 | Aspecto de la avenida Benito Juárez sin y con tianguis}

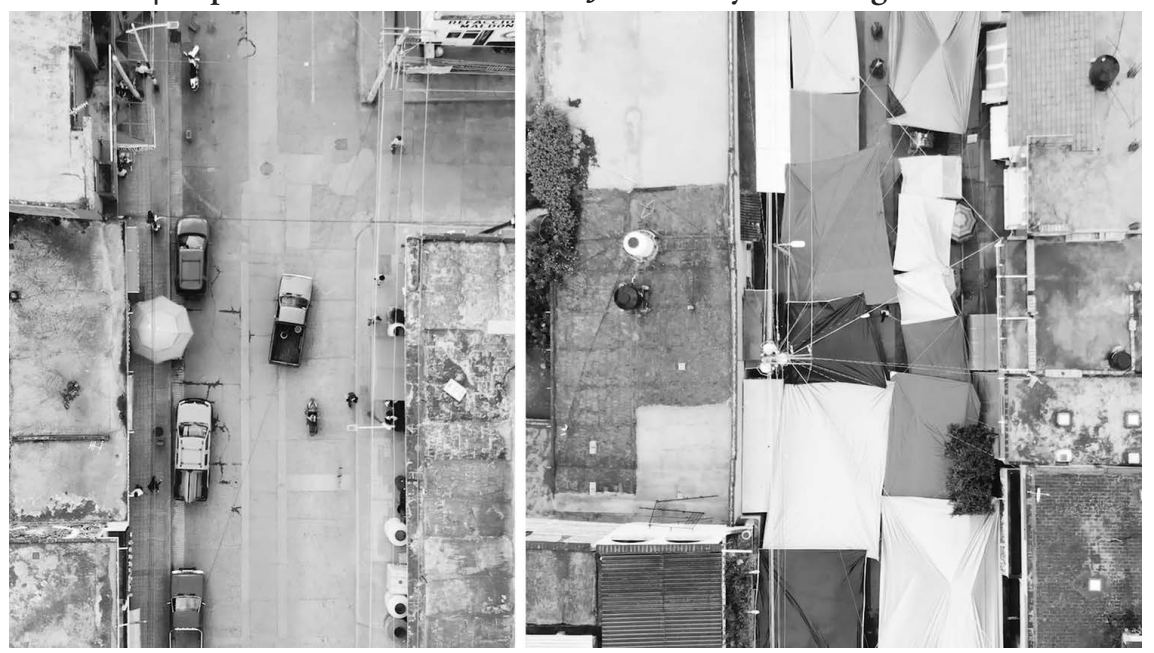

FUENTE: FOTOGRAFÍAS DE BERNARDO DE ANDA Y BRUNO SEVE

Finalmente, en cuanto a derecho de ocupación de espacio, nuestro estudio muestra que sí existe una regulación y un pago para ocupar un puesto en la calle (entre 10 y 25 pesos, según el lugar y la superficie). Todo indica que son las y los marchantes quienes ocupan primero el sitio, y después piden el permiso al municipio (en un $85 \%$ de los casos), lo cual se suele aceptar fácilmente, mientras que un 5\% declara haber sido reubicado y a un 5\% le asignó el lugar el municipio. Estos datos muestran generalmente que se trata primero de una autoorganización a la cual se adapta 
una regulación. No obstante, en algunos casos, el gobierno municipal que otorga y cobra permisos tiene algunos efectos en la autoorganización. Se denotan entonces varias maneras de ocupar el espacio, con una cierta diferenciación no normalizada oficialmente, surgida de forma natural a través del tiempo a partir de la transformación de la naturaleza de los productos que se van expendiendo, y del uso cotidiano del espacio que hacen primordialmente los vendedores. Los expendedores originarios del área urbana del municipio de Tlacolula han conformado esta particular distribución espacial que, en los tiempos actuales, continúa funcionando tal vez como en sus orígenes. Los aspectos derivados de la práctica del tianguis se preservan dentro de la modernidad actual y desempeñan un papel muy importante para la economía y cultura de una región particular, como es el distrito de Tlacolula.

\section{Análisis espacial del tianguis: \\ tipologías y diversidad de los puestos y sus marchantes}

La recopilación de datos a través de la conversación con las y los marchantes nos ha permitido encontrar las unidades básicas arquitectónicas del sistema de tianguis de Matamoros, en que destaca una gran ingeniosidad para la construcción de sus puestos, labor que se realiza de diversas maneras, desde lo más simple a sistemas más complejos, aunque tradicionales. El fenómeno más destacable sigue siendo la gran red de lonas, que permite proteger a la vez de la lluvia y del sol no solo el puesto, sino también una parte del área de circulación de los peatones, brindado así comodidad en el recorrido. La suma de los puestos, de las lonas y de la mercancía es la que da finalmente forma al gran sistema del tianguis. En este sistema, podemos definir cuatro grupos de puestos (a, b, c, d, Figura 9).

La forma más minimalista de ocupar el espacio está definida en el grupo (a) (ver Figura 9), desde las y los marchantes, ambulantes y fijos. Josefina, de 45 años, acompañada de su "diablito" -un transporte metálico vertical de dos ruedas, una caja de madera (también llamado "huacal", palabra proveniente del náhuatl y que denomina a una jaula o cesta hecha de carrizo o palma, utilizada para transportar víveres)-, vende colgadores metálicos y plásticos para colgar la mercancía. Pedro, de 32 años, carga en una maleta su ingeniosa mesa desplegable, que afirma acomodar en dos minutos para la venta de sus dulces de jalea y frutas naturales. Para sentarse, utiliza su triciclo de bicicleta. Julia, de 58 años, recurre a costales, cestas y canastos de carrizo y un banco donde sentarse para la venta de cacahuates, nueces y jícamas. En este grupo se suele utilizar solo dos componentes: algún elemento para exponer la mercancía, que puede ser el suelo directamente, un tapete, cajas de frutales (de plástico o huacales de madera); y un lugar para sentarse.

El segundo grupo de puestos (b), es una combinación del grupo (a) con algún tipo de protección, como una lona para cubrir del sol y de la lluvia. Cabe mencionar que muchos de los comerciantes que entran en la primera categoría (a) poseen la lona, pero la levantan según las necesidades de los distintos comerciantes o del lugar, ya que las lonas de algunos marchantes pueden proteger el espacio de otros, o la propia arquitectura en el lugar ya proporciona la sombra o la protección requerida. El sistema de lonas se amarra a postes que el municipio colocó para este fin en la acera, pero también sobre apoyos como postes de teléfono o de luz, herrerías de ventanas o 
puertas de comercios o casas. El señor Paulino, de 60 años, cuenta, por ejemplo, que paga 10 pesos (50 céntimos de euro) para ocupar el sitio cada domingo y vende sus manualidades y objetos de arte directamente en el suelo, pero recubierto con una lona. Según él, sus ventas han mejorado al resultar más atractiva la colocación de su mercancía en el suelo. La mayoría de las artesanías de barro, como cazuelas - por ejemplo, las de la señora Valentina, de 45 años, con sus artesanías de barro rojo; o las de la señora Filogenia, con su alfarería verde-, se colocan en el suelo, mientras la ropa y los alimentos suelen exponerse en puestos a la altura de una mesa. En cuanto a la venta de frutas o especias, se suele colocar los productos a una altura de mesa; un ejemplo es el caso de la seńora Ofelia, de 37 años, que utiliza bancos de hierro con cubierta de madera y un mantel de plástico, cajas grandes de plástico o cubetas pequeñas de plástico para mostrar la fruta, y la lona para cubrir el puesto.

\section{FIGURA 9 | Tipologías de puestos}

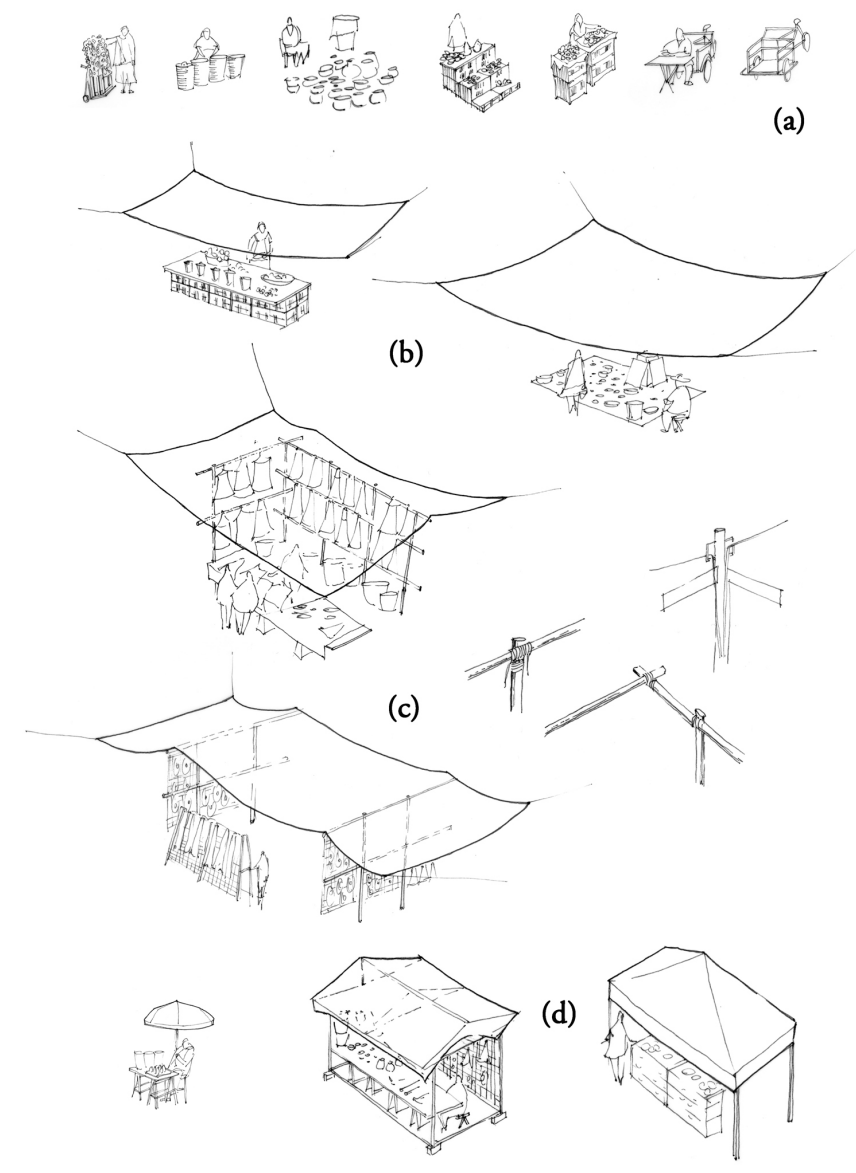

FUENTE: ELABORADO POR BRUNO SEVE 
El tercer grupo (c) (ver Figura 9), que tiene un grado más de complejidad, comprende la venta de ropa y textiles. Se ańade a la lona una estructura vertical de madera, con sistemas de ganchos o rejillas para colocar la ropa. En este caso es el propio peso de las lonas lo que proporciona estabilidad a la estructura, haciendo innecesario disponer de bases y dejando los morillos apoyados directamente en suelo. La señora Alicia, de 63 ańos, explica que instala este tipo de puesto en una hora, con la ayuda de sus hijos. Acude al tianguis desde hace 43 ańos, aunque antes tenía un puesto dentro del mercado cubierto; pero, por trabajos de mantenimiento y restauración, algunos comerciantes fueron reubicados provisionalmente en la calle. Al terminar dichos trabajos, por un conflicto entre grupos de comerciantes y al no poder comprobar su permiso, perdió su puesto en el interior del mercado. Ahora ocupa un puesto prestado en el tianguis, donde expende textiles (mandiles) de Mitla. Su puesto está formado por dos mamparas con soportes verticales de morillos de madera y horizontales de madera, amarrados entre sí con tiras de tela. Estas mamparas sirven para colgar los textiles y configuran un sistema en un ángulo de 90 grados. Al frente se instala una mesa con apoyos ("caballetes") metálicos (también llamados en México "burritos"), sobre los cuales se colocan tablas de madera; y sobre estas, una tela donde se exhiben las prendas textiles. Sobre este sistema de mamparas y mesa se instala el manteado, que tiene ya incorporadas unas especies de jaretas de las cuales se amarra la estructura vertical de madera, y que también sirven para colgar piezas textiles. Este manteado textil, que protege del sol, tiene sobre sí una lona plástica que resguarda en caso de lluvia, lográndose así un sistema combinado que resulta más fresco que si solamente se usara lona plástica, y más impermeable que si solo fuera manteado textil. La señora Alicia menciona que para lograr la tensión necesaria en el sistema de cubierta con doble capa -tela y plástico-, ello se debe realizar desde los balcones cercanos de casas, a cuyos propietarios se les paga 10 pesos por cada mecate ${ }^{11}$ utilizado, generándose así un ingreso informal a los propietarios de los balcones. También relata que en esta calle donde ella tiene su puesto no hay postes, lo que le permite evitar ese pago, y que dichos postes han sido solicitados a candidatos en campańa o regidores de mercado en funciones, aunque no ha habido respuesta satisfactoria.

Finalmente, el último grupo (d), representa variantes de combinaciones. En él encontramos las llamadas "casetas", constituidas por una estructura de perfil tubular de acero, la cual se ensambla sin necesidad de amarres. Tiene largueros verticales y horizontales que definen el espacio del puesto, así como una rejilla metálica. Según la señora Guadalupe, que vende artesanías de palma, madera, carrizo y bolsas de plástico hechas en la Mixteca, la forma y materiales de esta tipología fue determinada por el municipio en un intento de uniformizar la imagen del tianguis en las primeras secciones. Estas últimas corresponden al emplazamiento más central de la ciudad, en el zócalo y cerca del templo. En el interior se encuentra la mesa con sus caballetes, tablas o carrizo, mantel sobre el cual se colocan las mercancías; bajo esta mesa se guardan objetos como las reservas de mercancías, artículos personales y

11 Dicc. Rae: mecate: 1. m. Am. Cen., Méx. y Ven. Cordel o cuerda hecha de cabuya, cáńamo, pita, crin de caballo o un material similar. [N. de E.] 
equipo de transporte, como "diablitos" o carretillas. Sobre este armazón se colocan de dos a cuatro cerchas triangulares metálicas que definen el perfil a dos pendientes sobre las cuales se instala lona plástica para protegerse de la lluvia y el sol, aunque, sin embargo, generan un exceso de calor, según la comerciante. De esta estructura de la cubierta se cuelgan mercancías. La instalación de esta tipología no demora más de una hora. Cabe aquí reflexionar sobre esta última tipología que se impone a los comerciantes, que cambia la atmósfera y la morfología del tianguis. Las "casetas" no proporcionan, como los ingeniosos sistemas inventados de lonas, una continuidad de protección a los visitantes, y no permiten el sistema de doble capa que ventila de forma natural el puesto. El riesgo de imponer modelos "preconcebidos" muestra la simplificación de modelos tradicionales, con construcciones incapaces de cumplir su función como sistema. Aunque se puede comprender la intención del municipio al regular estos puestos en la zona llamada "los adoquines", justo en frente de Santa María de la Asunción, quizás la regulación hubiera tenido más sentido si se hubiera propuesto una versión reinterpretada de tianguis tradicional. No obstante, y felizmente, en el tianguis de Tlacolula de Matamoros las tipologías son diversas y las lonas no desaparecen de las calles.

\section{Conclusión}

Los tianguis son aún un ejemplo vivo de un sistema emergente y complejo, que depende de una serie de criterios sociológicos, históricos, culturales y espaciales del lugar y de la población local. Es un equilibrio hoy fragilizado por la llegada de la era neoliberal a los valles centrales de Oaxaca. Como se ha mencionado anteriormente, un cierto grado de neoliberalización de la sociedad en los valles centrales de Oaxaca (Benítez Hernández \& Enríquez Valencia, 2018) se ha hecho patente con la llegada de grandes malls y supermercados, de marca generalmente estadounidense, a apenas una hora de camino. No obstante, el tianguis de Tlacolula de Matamoros sigue siendo un lugar con una extraordinaria diversidad de población, un espacio en el cual cada uno aporta su parte y participa en el funcionamiento de aquella ciudad efímera. Se trata de una diversidad que, sin ninguna duda, podemos comparar a la biodiversidad, exclusiva de la naturaleza, pero que empezamos a entender para planear las ciudades, hecho que ya relató Jane Jacobs en su libro Muerte y vida de las grandes ciudades (1961), donde hablaba de sistemas complejos en las ciudades, que parten de sus usuarios. En este contexto, y en el caso concreto de Tlacolula de Matamoros, parece ser que el derecho al trabajo está por encima del espacio público, aunque se deben manejar estos conceptos con precauciones. Esta condición en el espacio público se hace posible gracias a un sistema muy complejo. Y si bien es difícil de trasladar a otro lugar, sí se puede estudiar y analizar con miras a su protección y a fin de proponer nuevos retos para ciudades futuras, integrando nociones de urbanismo de abajo hacia arriba.

Lo anterior significa para nosotras y nosotros, arquitectas, arquitectos y urbanistas, que, al repensar los espacios públicos, debemos tener el gran cuidado de no formalizar conceptos y formas radicalmente sencillas que no tienen en cuenta todos los aspectos del lugar y, principalmente, a su población. El equilibrio del sistema de 
mercados no puede estar reordenado desde un punto de vista solo espacial y arquitectónico. La vitalidad de los tianguis depende directamente de factores complejos a gran escala, como la ubicación en el valle y la relativa proximidad a Oaxaca, y la flexibilidad y facilidad con la cual las y los marchantes se pueden instalar alrededor del centro urbano. Existe, además, una dimensión ecológica y sostenible del modelo, aunque otros estudios revelan también una precariedad creciente en los y las participantes de los mercados. A pie de calle, la diversidad de tipología de la arquitectura espontánea de los puestos autoinstalados por los ofertantes, y su calidad espacial y atmosférica, nos enseña cómo la arquitectura también trata de dejar sitio a la libre creación de los habitantes de la región. La solución del problema a gran escala de la neoliberalización debe pasar, por supuesto, por una limitación de las grandes marcas y supermercados en los valles centrales de Oaxaca. El objetivo debe ser no repetir errores ya cometidos en otros lugares, que no han sabido proteger los comercios de proximidad y han permitido que se transformen en negocios dirigidos solo al turista, creando una monocultura y arquitectura baratas de consumo que -ya lo sabemos- no son una solución sostenible. En este sentido, el "hacer la ciudad" y la mejora de nuestros espacios urbanos pasa necesariamente por el apoyo y la reinterpretación de lo que ya funciona y beneficia a su propia población.

\section{Agradecimientos}

Esta investigación ha sido apoyada por el Programa Estatal de Investigación, Desarrollo e Innovación orientada a los Retos de la Sociedad con referencias BIA2OI6-77464-C2-I-R у BIA2OI6-77464-C2-2-R. Ambas forman parte del Plan Nacional para Investigación Científica, Desarrollo e Innovación Tecnológica 20132016, del Gobierno de España.

\section{Referencias bibliográficas}

Ageo (Archivo General del Estado de Oaxaca). Gobierno, industria y comercio, exp. 14, Mercados y tianguis, 1828 .

Ageo (Archivo General del Estado de Oaxaca). Gobierno, industria y comercio, exp. 15, Mercados y tianguis, 1835 .

AGEO (Archivo General del Estado de Oaxaca). Gobierno, industria y comercio, exp. 22, Mercados y tianguis, 1858 .

AGEO (Archivo General del Estado de Oaxaca). Gobierno, industria y comercio, exp. 27, Mercados y tianguis, 1875 .

AGEo (Archivo General del Estado de Oaxaca). Gobierno, industria y comercio, exp. 28, Mercados y tianguis, 1879 .

AGEO (Archivo General del Estado de Oaxaca). Gobierno, industria y comercio, exp. 56, Mercados y tianguis, 1896.

AGEO (Archivo General del Estado de Oaxaca). Gobierno, industria y comercio, exp.4, Mercados y tianguis, 1926. 
Álvarez, L. R. (2008). Historia general del estado de Oaxaca. Siena Editores.

Arnstein, R. (1969). A ladder of citizen participation. Journal of the American Planning Association, 35(4), 216-224. https://doi.org/10.1080/01944366908977225

Ascher, F. (2010). Les nouveaux principes de l'urbanisme. Éditions de l'Aube.

Benítez Hernández, C. T. \& Enríquez Valencia, E. (2018). El mercado tradicional en Tlacolula de Matamoros y la economía campesina local. En C. Bayón, S. Ochoa \& J. G. Rivera González (Coords.), Desigualdades, pobreza, economía informal, precariedad laboral y desarrollo económico. Vol. 3 de Las ciencias sociales y la agenda nacional. Reflexiones y propuestas desde las Ciencias Sociales, coordinado por J. Cadena Roa, M. Aguilar Robledo y D. E. Eduardo Vázquez Salguero (pp. 1091-1106). Consejo Mexicano de Ciencias Sociales (COMECSO). https://www.comecso.com/ciencias-sociales-agendanacional/cs/issue/view/3/3

Bravo, P. (2016, octubre 20). ¿Se puede hacer una ciudad para las personas sin cambiar la economia? Eldiario.es. https://www.eldiario.es/desde-mi-bici/hacer-ciudad-personascambiar-economia_132_3774942.html

Centro de Información Estadística y Geográfica del estado de Oaxaca (CEIEG). (2010). Ficha distrital Tlacolula. Gobierno del estado de Oaxaca. http://ceiegoaxaca.gob.mx/sim/ distrito/reporte_reg_mx.php?cve_dtorn $=20$.

Chance, J. K. (1993). Razas y clases en la Oaxaca colonial. Serie Presencias, 63. Instituto Nacional Indigenista (INI), México.

Cook, S. \& Diskin, M. (1990). Análisis e historia en la economía de mercado campesino del Valle de Oaxaca. En M. Diskin \& S. Cook (Eds.), Mercados de Oaxaca (pp. 25-53). Consejo Nacional para la Cultura y las Artes, Instituto Nacional Indigenista, México.

Cordero Avendaño de Durand, C. (1982). Supervivencia de un derecho consuetudinario en el Valle de Tlacolula. Fondo Nacional Para Actividades Sociales (fonapas), Oaxaca, México.

Coronel, D. (2006). Zapotecos de los Valles Centrales de Oaxaca. Pueblos indígenas del México contemporáneo. Comisión Nacional para el Desarrollo de los Pueblos Indígenas (CDI), México.

De Molina, A. (1555). Aquí comienca (sic) un vocabulario de la lengua castellana y mexicana. Editorial Juan Pablos. http://www.cervantesvirtual.com/nd/ark:/59851/bmc697h9

Delgado, M. (2007). La ciudad mentirosa, fraude y miseria del modelo. Editorial Catarata.

Diskin, M. \& Cook, S. (1975). Mercados de Oaxaca. Instituto Nacional Indigenista (INI), México.

Duhau, E. (1988). Mercado interno y urbanización en el México colonial. Editorial Gernika, Universidad Autónoma Metropolitana (UAM), México.

Gordon, D. (2010). Ant encounters: Interaction networks and colony behavior. Princeton University Press.

Grosso, J. (1989). El tianguis de Tepeaca a fines del siglo XVIII. Lecturas Históricas de Puebla, 27. Gobierno del Estado de Puebla, Secretaría de Cultura, México.

Hernández, E. (1996). Vocabulario en lengua castellana y mexicana de fray Alonso de Molina. Consejo Superior de Investigaciones Científicas (CSIC), España.

Jacobs, J. (1961). The death and life of great American cities. Random House.

Johnson, S. (2001). Emergence: The connected lives of ants, brains, cities, and software. Allen Lane.

Kim, A. M. (2015). Sidewalk city: Remapping public space in Ho Chi Minh City. The University of Chicago Press. 
Lazo, P. (2006). Ensamblado en México. Los mercados sobre ruedas como alternativa de espacio público. Arquine (verano), 36, 85.

Malinowski, B. \& De la Fuente, J. (2005 [1957]). La economía de un sistema de mercados en México: Un ensayo de etnografía contemporánea y cambio social en un valle mexicano ( $2^{\mathrm{a}}$ edición). Instituto Nacional de Antropología e Historia, México.

Marcus, J. (2008). Monte Albán. Fondo de Cultura Económica.

Muxí, Z. \& Gutiérrez, B. (2011). Apuntes sobre Jane Jacobs. En J. Jacobs, Muerte y vida de las grandes ciudades (p. 13). Capitán Swing.

Neruda, P. (1974). Confieso que he vivido. Seix Barral.

Nolasco, M. (1981). Cuatro ciudades. El proceso de urbanización dependiente. Instituto Nacional de Antropología e Historia (INAH), México.

Santos, M. \& Mendoza, E. (2009). El mercado tradicional de Miahuatlán de Porfirio Díaz y la participación de las mujeres. En A. Luna (Coord.), Género, sociedad y cultura. Análisis multidisciplinario de las dinámicas socioeconómicas, históricas, culturales y psicológicas de las mujeres en la Sierra Sur Oaxaqueña (pp. 87-105). Fundación Universitaria Andaluza Inca Garcilaso, Universidad de Málaga. http://www.eumed.net/libros/2009a/503/ index.htm

Taylor, W. B. (s/f). Haciendas coloniales en el valle de Oaxaca. Universidad de Colorado.

Turner, J. F. C. (2018). Autoconstrucción. Por una autonomía del habitar. Escritos sobre vivienda, urbanismo, autogestión y holismo. Pepitas de Calabaza.

Warman, A. (1982). Prólogo: Acciones y costumbres centenarias. En Mercados indios. Instituto Nacional Indigenista (INI), Fondo Nacional para las Actividades Sociales (FONAPAS), México. 